\title{
Cuidado de enfermagem a mulher vítima de violência sexual: uma revisão
} integrativa da literatura

\author{
Nursing care for a woman victim of sexual violence: a integrative literature review \\ Atención de enfermería a mujeres víctimas de violencia sexual: revisión integradora de la literatura
}

Recebido: 02/02/2021 | Revisado: 07/02/2021 | Aceito: 10/02/2021 | Publicado: 17/02/2021

Liandre Padilha Machado

ORCID: https://orcid.org/0000-0002-0137-3621

Universidade de Cruz Alta, Brasil

E-mail: liaandremachado@hotmail.com

Vera Lucia Freitag

ORCID: https://orcid.org/0000-0002-5897-7012

Universidade de Cruz Alta, Brasil

E-mail: verafreitag@hotmail.com

\begin{abstract}
Resumo
Objetivo: investigar na literatura científica o cuidado de enfermagem á mulher vítima de violência sexual. Metodologia: revisão integrativa da literatura. A questão norteadora foi: qual a produção científica acerca do cuidado de enfermagem as mulheres vítimas de violência sexual. Os descritores foram: cuidados de enfermagem; delitos sexuais e mulheres, e, cuidados de enfermagem; mulheres e o termo alternativo, abuso sexual, realizada na Biblioteca Virtual da Saúde (BVS), elencando as bases de dados: Literatura Latino-Americana e do Caribe em Ciências da Saúde (LILACS), Biblioteca Virtual de Enfermagem (BDENF), Sistema Online de Busca e Análise de Literatura Médica (MEDLINE) e Índice Bibliográfico Español en Ciencias de la Salud (IBECS). Após aplicado os critérios de inclusão e exclusão, selecionou-se oito artigos para a amostra final. A partir dos resultados, elaborou-se um tema: Resultados: o cuidado de enfermagem a mulher vítima de violência sexual. Estes mostraram que existem lacunas em relação ao cuidado prestado pelos profissionais de enfermagem, seja pela forma de acolhimento/abordagem/cuidado, bem como a não utilização de protocolos específicos de atendimento, havendo falhas no encaminhamento dos casos. Ainda, observou-se que onde acontecia um acolhimento humanizado, as mulheres sentiam-se mais a vontade para relatar o ocorrido. Conclusão: faz necessário que os profissionais de saúde, em especial a enfermagem, adquiram conhecimento sobre este complexo cuidado, capacitando-se para a efetividade das ações, cuidando na integralidade e expondo a mulher o mínimo possível, compreendendo a complexidade da dor que perpassa o físico, o qual impacta significantemente no emocional e desestrutura sua vida e maneira de viver.
\end{abstract}

Palavras-chave: Enfermagem; Violência sexual; Mulheres; Cuidado.

\begin{abstract}
Objective: to investigate in the scientific literature nursing care for women who are victims of sexual violence. Methodology: integrative review of the literature. The main question was: what is the scientific production about nursing care for women victims of sexual violence. The descriptors were: nursing care; sexual offenses and women, and nursing care; alternative term, sexual abuse, carried out in the Virtual Health Library (VHL), by establishing the databases: Latin American and Caribbean Literature on Health Sciences (LILACS), Virtual Nursing Library (BDENF), Online Medical Literature Search and Analysis System (MEDLINE) and Bibliographic Index Español en Ciencias de la Salud (IBECS). After applying the inclusion and exclusion criteria, eight articles were selected for the final sample. Based on the results, a theme was elaborated: Results: nursing care for women who are victims of sexual violence. These showed that there are gaps in relation to the care provided by nursing professionals, either by the form of reception/approach/care, as well as the non-use of specific care protocols, with failures in the referral of cases. Furthermore, it was observed that where a humanized welcome took place, women felt more comfortable to report what happened. Conclusion: it makes it necessary for health professionals, especially nursing, to acquire knowledge about this complex care, training themselves for the effectiveness of actions, taking care of the whole and exposing the woman as little as possible, understanding the complexity of the pain that permeates the physical, which significantly impacts on the emotional and disstructure of her life and way of living.
\end{abstract}

Keywords: Nursing; Sexual violence; Women; Care.

\section{Resumen}

Objetivo: investigar en la literatura científica la atención de enfermería para las mujeres víctimas de violencia sexual. Metodología: revisión integrativa de la literatura. La pregunta principal era: ¿cuál es la producción científica sobre la 
atención de enfermería a las mujeres víctimas de violencia sexual. Los descriptores eran: cuidado de enfermería; delitos sexuales y las mujeres, y la atención de enfermería; término alternativo, abuso sexual, llevado a cabo en la Biblioteca Virtual de Salud (VHL), mediante el establecimiento de las bases de datos: Literatura Latinoamericana y del Caribe sobre Ciencias de la Salud (LILACS), Biblioteca Virtual de Enfermería (BDENF), Sistema de Búsqueda y Análisis de Literatura Médica en Línea (MEDLINE) y el Índice Bibliográfico Español en Ciencias de la Salud (IBECS). Después de aplicar los criterios de inclusión y exclusión, se seleccionaron ocho artículos para la muestra final. Sobre la base de los resultados, se elaboró un tema. Resultados: cuidado de enfermería para mujeres víctimas de violencia sexual. Esto demostró que existen lagunas en relación con la atención prestada por los profesionales de enfermería, ya sea por la forma de recepción/enfoque/cuidado, así como por la no utilización de protocolos de atención específicos, con fallas en la remisión de casos. Además, se observó que cuando se llevaba a cabo una acogida humanizada, las mujeres se sentían más cómodas para informar de lo sucedido. Conclusión: hace necesario que los profesionales de la salud, especialmente la enfermería, adquieran conocimientos sobre este complejo cuidado, entrenándose para la eficacia de las acciones, cuidando el conjunto y exponiendo a la mujer lo menos posible, entendiendo la complejidad del dolor que impregna lo físico, lo que impacta significativamente en lo emocional y de la desestructura de su vida y forma de vida.

Palabras clave: Enfermería; Violencia sexual; Mujeres; Cuidado.

\section{Introdução}

A violência tem mais de um sentido, é complexa e polissêmica, implica vários elementos e posições teóricas. Esta acontece das mais várias formas. Segundo Modena (2016), a violência pode ser natural, pois ninguém está livre da violência, ela é própria de todos os seres humanos, ou artificiais, quando a violência é geralmente um abuso de força de uns sobre outros. A prática da violência expressa atitudes contrárias à liberdade e à vontade de alguém, em que reside a dimensão moral e ética.

O termo violência é a qualidade ou característica de violento, ato de crueldade, ocupação de meios violentos, fúria repentina, coação que leva uma pessoa à sujeição de alguém (Michaelis, 2018). A Organização Mundial da Saúde (OMS) estabelece também distinções sobre as naturezas da violência, sendo que podem ser de origem: 1) física; 2) sexual; 3) psicológica; 4) relacionada à privação ou ao abandono (OMS, 2020).

No contexto da violência, a perpetrada contra a mulher atinge proporções alarmantes. Estudo que realizou um rastreio das violências por meio de um instrumento da OMS, em que participaram 991 mulheres, os resultados mostraram que as prevalências de violência, ao longo da vida, foram: psicológica 57,6\%; física 39,3\% e sexual 18,0\%. Ainda, as mulheres com até oito anos de estudo, cujas mães sofreram violência por parceiro íntimo, fizeram uso de drogas e foram acometidas pela violência sexual na infância, a prevalência foi maior nas três violências (Santos et al., 2020).

Em seu relatório, a OMS aponta que 35,0\% das mulheres no mundo relatam ter sofrido algum tipo de violência na vida, entre física e sexual (OMS, 2002). A violência sexual contra a mulher é a demonstração do poder do homem sobre a mulher, considerada violência de gênero, sendo uma agressão cruel, a qual causa danos, podendo interferir em questões como o bem-estar físico, a questões sexuais, reprodutivas, emocionais, mentais e sociais das mulheres acometidas pela violência (Santos et al., 2020).

Neste contexto, a violência sexual é qualquer ato sexual ou tentativa de realizar um ato sexual por violência, comentários ou avanços sexuais indesejados, ações para comercializar ou usar a sexualidade de uma pessoa, independentemente da relação deste com a vítima, em qualquer campo (Freire, 2018).

Atualmente no Brasil existem muitos casos de violência sexual contra as mulheres, há mais casos ocultos do que revelados, por motivos de medo por parte do abusador e a questão das mulheres abusadas se sentirem culpadas por tal ato faz com que, o abusador não seja levado às autoridades responsável para que este responda na justiça por seus atos (Jesus et al., 2019).

Um dos princípios que rege qualquer sociedade é o respeito com todos assim como com as diferenças, no Brasil estamos assegurados pela Constituição à igualdade perante a lei, sem distinção de qualquer natureza, garantindo-se aos 
brasileiros e aos estrangeiros residentes no País a inviolabilidade do direito à vida, à liberdade, à igualdade, à segurança e à propriedade. A Constituição afirma que "homens e mulheres são iguais em direitos e obrigações" (Brasil, 1988, p.14)

Nesta premissa, entende-se que o conceito de violência é muito complexo e envolve diversos fatores, elementos e posições teóricas, e em um país com vasto território como o Brasil ela está disseminada em diversas formas na sociedade, mas um grupo específico que sofre ao longo dos anos com diversos tipos de violência são as mulheres, que mesmo asseguradas por lei convivem diariamente com diversos tipos de violência que vão desde a psicológica a física.

Qualquer tipo de violência é algo repulsivo, mas a violência sexual além de afetar fisicamente sua vítima, afeta seu psicológico e as pessoas em seu convívio, é um fenômeno universal, em que não existem restrições de sexo, idade, etnia ou classe social. Embora atinja homens e mulheres, as mulheres são as principais vítimas, em qualquer período de suas vidas, apesar de na infância, adolescência e juventude, as mulheres apresentarem risco mais elevado de sofrer esse tipo de agressão.

A violência contra a mulher consiste em um problema de saúde pública, o que alerta para a importância dos profissionais perceberem esse agravo como objeto da saúde. No que se refere à violência sexual, em 2011, foram realizados mais de 13 mil atendimentos de mulheres no âmbito do SUS, com destaque para o estupro (Barros et al., 2015). Tal violência, configura-se como uma grave violação dos direitos humanos. Diante desta realidade, os profissionais da área da saúde devem estar instruídos e prevenidos emocionalmente para que possam enfrentar momentos de tensão no atendimento de vítimas de violência, fornecendo acompanhamento integral (Araújo et al., 2011).

Levando em consideração que o profissional de enfermagem é um dos primeiros a ter contato com a vítima desse tipo de violência, ele deve estar-bem preparado e capacitado para atender esse tipo de situação, este estudo buscou responder a seguinte questão pesquisa é: Qual a produção científica acerca do cuidado de enfermagem as mulheres vítimas de violência sexual? Sendo assim, o objetivo do estudo foi: Investigar na literatura cientifica o cuidado de enfermagem à mulher vítima de violência sexual.

\section{Metodologia}

Este estudo foi realizado por meio da revisão integrativa da literatura, a partir de artigos científicos publicados nas bases de dados virtuais de saúde referentes à Violência Sexual contra as mulheres, elaborado no curso de Enfermagem da Universidade de Cruz Alta (UNICRUZ), como requisito parcial para o grau de Enfermeira.

A revisão integrativa consiste na análise de pesquisas relevantes, propondo diferenciar a tomada de decisão e a melhoria da prática clínica, possibilitando o avanço do conhecimento (Mendes; Silveira \& Galvão, 2008).

Na realização dessa revisão, utilizou-se as seguintes etapas: seleção da pergunta, estabelecimento dos critérios para seleção da amostra, análise dos dados, interpretação dos resultados, discussão da revisão e conclusão (Mendes; Silveira \& Galvão, 2008).

Para a busca das informações elaborou-se a seguinte questão pesquisa: qual a produção científica acerca do cuidado de enfermagem as mulheres vítimas de violência sexual. Para a realização da pesquisa foi utilizado a combinação dos seguintes Descritores em Ciências da Saúde (DECS): cuidados de enfermagem AND delitos sexuais AND mulheres, e, cuidados de enfermagem AND mulheres AND abuso sexual. As palavras 'abuso sexual' faz parte dos termos alternativos. Com os descritores: cuidados de enfermagem AND delitos sexuais AND mulheres na Biblioteca Virtual da Saúde, emergiu 36 artigos. Seguidamente foram aplicados os critérios de inclusão: texto completo, idiomas: inglês, português, espanhol e limite temporal, artigos publicados nos últimos dez anos, de (2010 a 2020), obteve-se 20 artigos, assim distribuídos: na Literatura LatinoAmericana e do Caribe em Ciências da Saúde (LILACS) 9, Biblioteca Virtual de Enfermagem (BDENF) 6, Sistema Online de Busca e Análise de Literatura Médica (MEDLINE) 3 e Índice Bibliográfico Español en Ciencias de la Salud (IBECS) 2. Após, realizou-se a leitura dos títulos e resumos a fim de buscar resposta ao objetivo da pesquisa, assim, selecionou-se 8 artigos para 
a leitura completa, sendo LILACS 4, BDENF 2, IBECS 0 e MEDLINE 2. Ao aplicar os critérios de exclusão, que foi: artigos repetidos, teses e dissertações, 2 artigos foram excluídos, um deles por repetição na mesma base de dados e o outro por ser uma tese. Assim sendo ficaram distribuídos LILACS 2, BDENF 2, MEDLINE 2. Então foram selecionados 6 artigos, por estarem relacionados ao objetivo desse estudo e atentar os critérios de inclusão e exclusão estabelecidos.

Com os descritores: cuidados de cuidados de enfermagem AND mulheres AND abuso sexual na Biblioteca Virtual da Saúde emergiu 123 estudos. Aplicou-se os mesmos critérios de inclusão, assim emergiu: 52 artigos, sendo: LILACS: 13, MEDLINE: 33, BDENF: 14 e IBECS: 3. Após a leitura minuciosa dos títulos e resumos, elencou-se 5 artigos para a leitura final: LILACS: 0, MEDLINE: 3, BDENF: 1 e IBECS: 1. Após aplicar os critérios de exclusão, ficaram assim distribuídos: LILACS: 0, MEDLINE: 2, BDENF: 1 e IBECS: 0. A seleção dos estudos está disposta no fluxograma abaixo:

Figura 1: Processo de inclusão dos artigos selecionados na revisão.

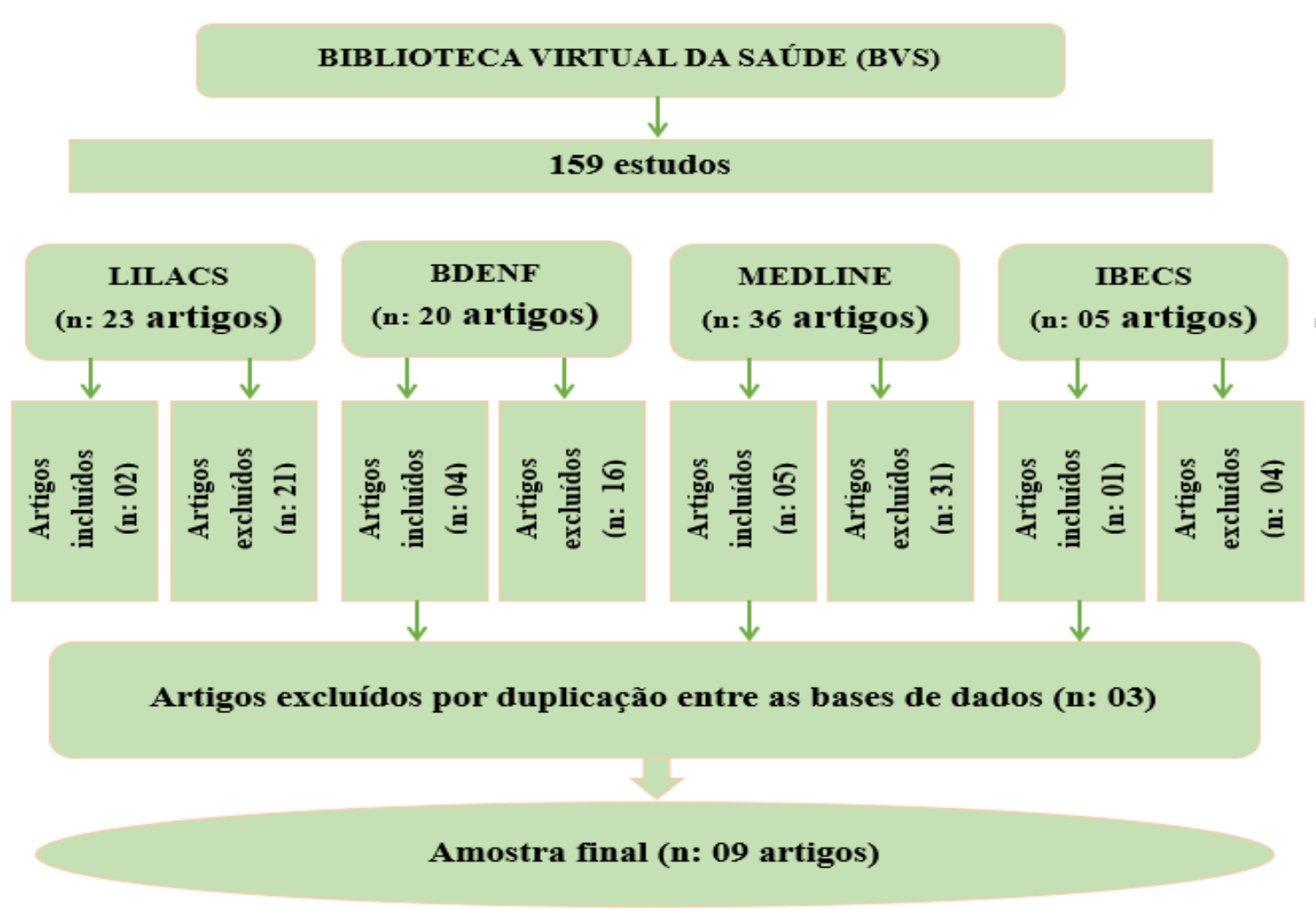

Fonte: Machado \& Freitag (2020).

Observa-se que dos 159 estudos, os quais emergiram na busca junto a Biblioteca Virtual de Saúde (BVS), após os critérios de inclusão e exclusão, a amostra final foi de nove estudos, os quais responderam a questão pesquisa e o objetivo da pesquisa.

\section{Resultados}

Os resultados obtidos dos estudos são selecionados em bases de dados, na qual são citados os títulos dos artigos, ano de publicação, periódico, autores (as), país, objetivo do estudo, metodologia, resultados e conclusão, como no Quadro 1. 
Quadro1: Distribuição dos estudos localizados na base de dados LILACS, MEDLINE e BDENF e IBECS, compreendendo o período de 2010 a 2020.

\begin{tabular}{|c|c|c|c|c|}
\hline $\begin{array}{c}\text { Título/Ano/Periódico/A } \\
\text { utores/País }\end{array}$ & Objetivo & Metodologia & Resultados & Conclusão \\
\hline $\begin{array}{l}\text { Título: Percepções de } \\
\text { enfermeiros da atenção } \\
\text { primária no atendimento } \\
\text { às mulheres vítimas de } \\
\text { violência sexual. } \\
\text { Ano: } 2020 \\
\text { Periódico: } \\
\text { Nursing } \\
\text { Autores: Mota, J. A., \& } \\
\text { Aguiar, R. S }\end{array}$ & 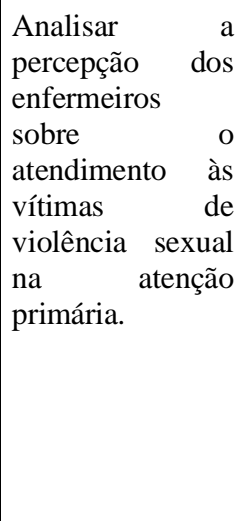 & $\begin{array}{l}\text { Estudo descritivo } \\
\text { exploratório com } \\
\text { abordagem } \\
\text { qualitativa, } \\
\text { desenvolvido com } \\
\text { sete enfermeiros de } \\
\text { uma unidade básica } \\
\text { de saúde do Distrito } \\
\text { Federal. }\end{array}$ & 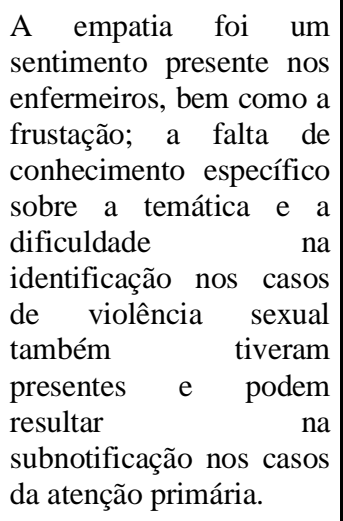 & $\begin{array}{l}\text { Torna-se uma abordagem } \\
\text { indireta do enfermeiro ás } \\
\text { mulheres através de } \\
\text { questionamentos sobre a } \\
\text { ocorrência de violência } \\
\text { sexual, bem como a } \\
\text { incorporação da temática } \\
\text { na graduação e a } \\
\text { realização de educação } \\
\text { permanente a a } \\
\text { profissionais. }\end{array}$ \\
\hline $\begin{array}{l}\text { Tìtulo: A percepção da } \\
\text { vítima de violência } \\
\text { sexual quanto ao } \\
\text { acolhimento em um } \\
\text { hospital de referência no } \\
\text { Paraná. } \\
\text { Periódico: } \\
\text { Revista de Pesquisa } \\
\text { (Universidade Federal do } \\
\text { Estado Rio Janeiro, } \\
\text { Online) } \\
\text { Ano: 2020 } \\
\text { Autores: Batistetti, L. } \\
\text { T., Lima, M. C. D. D., \& } \\
\text { Souza, S. R. R. K. } \\
\text { País: Brasil }\end{array}$ & $\begin{array}{lr}\text { Identificar } & \text { a } \\
\text { percepção } & \text { das } \\
\text { vítimas } & \text { de } \\
\text { violência } & \text { sexual } \\
\text { em relação } & \text { ao } \\
\text { acolhimento } & \\
\text { prestado } & \text { pela } \\
\text { equipe } & \text { de } \\
\text { enfermagem } & \text { no } \\
\text { pronto } & \\
\text { atendimento } & \text { de } \\
\text { hospital } & \\
\text { referenciado em } \\
\text { Curitiba, Paraná. }\end{array}$ & $\begin{array}{lr}\text { Pesquisa } & \text { descritiva } \\
\text { de } & \text { abordagem } \\
\text { qualitativa } & \text { com } \\
\text { mulheres vítimas de } \\
\text { violência } & \text { sexual } \\
\text { atendidas } & \text { em } \\
\text { ambulatório } & \text { nos } \\
\text { meses de julho } & \text { a } \\
\text { agosto de } 2017 \text {. A } \\
\text { coleta dos dados foi } \\
\text { por mero } \\
\text { entrevista } \\
\text { semiestruturada } \\
\text { analisados por meio } \\
\text { de análise } \\
\text { conteúdo. }\end{array}$ & $\begin{array}{l}\text { Evidenciou-se como o } \\
\text { cuidado prestado não } \\
\text { somente procedimentos } \\
\text { técnicos, mas também o } \\
\text { cuidado individualizado } \\
\text { às necessidades e a } \\
\text { presença constante do } \\
\text { profissional durante o } \\
\text { atendimento, embora } \\
\text { algumas entrevistadas } \\
\text { desconhecessem a } \\
\text { categoria profissional } \\
\text { deste. }\end{array}$ & $\begin{array}{l}\text { A enfermagem carece de } \\
\text { reconhecimento social, } \\
\text { porém seu atendimento } \\
\text { foi reconhecido como } \\
\text { positivo pelas mulheres e } \\
\text { gerador de sentimentos } \\
\text { de proteção } \\
\text { acolhimento. }\end{array}$ \\
\hline $\begin{array}{l}\text { Título: O processo de } \\
\text { resiliência em mulheres } \\
\text { vítimas de violência } \\
\text { sexual: } \\
\text { possibilidade de cuidado. } \\
\text { Ano: } 2018 \\
\text { Periódico: Revista } \\
\text { Cogitare Enfermagem. } \\
\text { Autores: Fornari, L. F., } \\
\text { \& Labronici, L. M. } \\
\text { País: Brasil }\end{array}$ & $\begin{array}{lr}\text { Conhecer } & \text { o } \\
\text { processo de } \\
\text { resiliência em } \\
\text { mulheres vítimas } \\
\text { de violência } \\
\text { sexual. }\end{array}$ & $\begin{array}{l}\text { Pesquisa exploratória } \\
\text { qualitativa, } \\
\text { fundamentada no } \\
\text { conceito } \\
\text { resiliência, realizada } \\
\text { com 12 mulheres } \\
\text { vítimas de violência } \\
\text { sexual, em um } \\
\text { Serviço } \\
\text { Atendimento } \\
\text { Especializado e uma } \\
\text { Delegacia da Mulher, } \\
\text { de um município } \\
\text { paranaense, de } \\
\text { setembro de } 2013 \text { a } \\
\text { fevereiro de } 2014 .\end{array}$ & $\begin{array}{l}\text { O sentimento de cuidado } \\
\text { e responsabilidade } \\
\text { promoveu a mobilização } \\
\text { interna, início do } \\
\text { processo de resiliência. } \\
\text { A presença de pessoas } \\
\text { dispostas a ouvir sem } \\
\text { julgar tornou possível a } \\
\text { representação do trauma } \\
\text { vivido pelas } \\
\text { participantes. } \\
\text { A religação com Deus e } \\
\text { a reativação da fé } \\
\text { forneceram estímulos } \\
\text { para acreditar que } \\
\text { sobreviver era mais } \\
\text { relevante do que ser } \\
\text { vítima. }\end{array}$ & $\begin{array}{l}\text { A pesquisa propiciou a } \\
\text { construção do } \\
\text { conhecimento } \\
\text { relacionado à resiliência } \\
\text { das mulheres vítimas de } \\
\text { violência sexual, e } \\
\text { mostrou a importância da } \\
\text { incorporação do tema no } \\
\text { cuidado de enfermagem. }\end{array}$ \\
\hline $\begin{array}{lr}\text { Título: O } & \text { sofrimento } \\
\text { psíquico no cotidiano de } \\
\text { mulheres r rue } \\
\text { vivenciaram a violência } \\
\text { sexual: } \\
\text { fenomenológico. } \\
\text { Ano: } 2017\end{array}$ & $\begin{array}{lr}\text { Compreender } & \text { as } \\
\text { ações } & \text { do } \\
\text { cotidiano de } & \text { de } \\
\text { mulheres que } & \text { vivenciaram } \\
\text { violência sexual. }\end{array}$ & $\begin{array}{l}\text { Pesquisa qualitativa, } \\
\text { realizada com } 11 \\
\text { mulheres } \\
\text { sofreram que } \\
\text { sexual, no siolência } \\
\text { Brasil. sul do } \\
\text { depoimentos foram } \\
\text { obtidos por meio de }\end{array}$ & $\begin{array}{l}\text { Evidenciou-se que o } \\
\text { cotidiano de mulheres, } \\
\text { após a violência sexual, } \\
\text { foi permeado pelo } \\
\text { sofrimento psíquico, } \\
\text { traduzido pelo medo que } \\
\text { impacta sua saúde } \\
\text { mental, limitando sua }\end{array}$ & 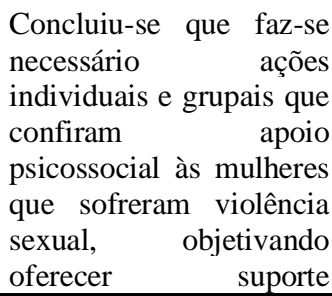 \\
\hline
\end{tabular}




\begin{tabular}{|c|c|c|c|c|}
\hline $\begin{array}{l}\text { Periódico: Revista de } \\
\text { Enfermagem da Escola } \\
\text { Anna Nery. } \\
\text { Autores: Trigueiro, T. } \\
\text { H., Silva, M. H. D., } \\
\text { Merighi, M. A. B., } \\
\text { Oliveira, D. M. D., \& } \\
\text { Jesus, M. C. P. D. } \\
\text { País: Brasil }\end{array}$ & & $\begin{array}{l}\text { entrevista } \\
\text { fenomenológica } \\
\text { realizada entre } \\
\text { outubro de } 2014 \text { e } \\
\text { abril de } 2015 \text {. }\end{array}$ & $\begin{array}{l}\text { vida, especialmente no } \\
\text { desempenho das } \\
\text { atividades sociais } \\
\text { (trabalho, escola e } \\
\text { relações afetivo-sexuais). }\end{array}$ & 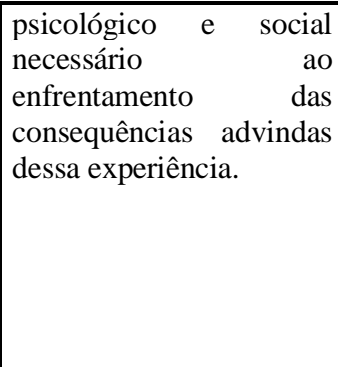 \\
\hline 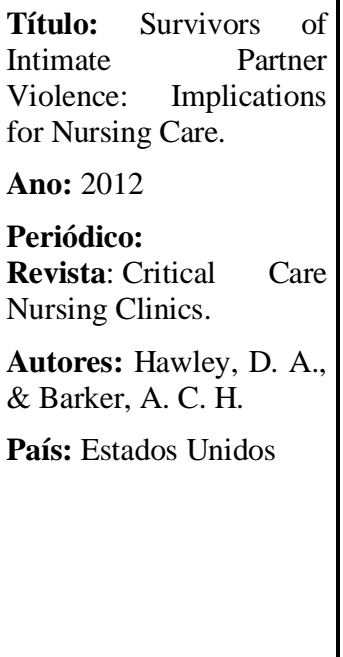 & $\begin{array}{lr}\text { Fornecer uma } \\
\text { visão sobre a } \\
\text { complexidade da } \\
\text { VPI em relação à } \\
\text { doença aguda } \\
\text { cuidar r r da } \\
\text { enfermagem, } \\
\text { bem r como } \\
\text { descrever r } \\
\text { dinâmica } & \text { a } \\
\text { psicológica } & \text { da } \\
\text { VPI. } & \end{array}$ & $\begin{array}{l}\text { Pesquisa qualitativa } \\
\text { que buscou analisar o } \\
\text { instrumento } \\
\text { RADAR, } \\
\text { desenvolvida pela } \\
\text { Massachusetts } \\
\text { Medical Society, R: } \\
\text { Realize a triagem de } \\
\text { rotina. A: Faça } \\
\text { perguntas diretas. D: } \\
\text { Documente as } \\
\text { descobertas. A: } \\
\text { Avalie a segurança } \\
\text { do paciente (e das } \\
\text { crianças). R: Analise } \\
\text { as opçôes do } \\
\text { paciente e forneça } \\
\text { referências. }\end{array}$ & $\begin{array}{l}\text { Os enfermeiros devem } \\
\text { compreender mais } \\
\text { especificamente } \\
\text { contexto da violência } \\
\text { sexual, bem como os } \\
\text { recursos da comunidade } \\
\text { disponíveis para os } \\
\text { sobreviventes desta } \\
\text { violência. Por último, os } \\
\text { enfermeiros precisam } \\
\text { reconhecer o suporte } \\
\text { físico, psicológico e } \\
\text { emocional que podem } \\
\text { dar a esses indivíduos. }\end{array}$ & 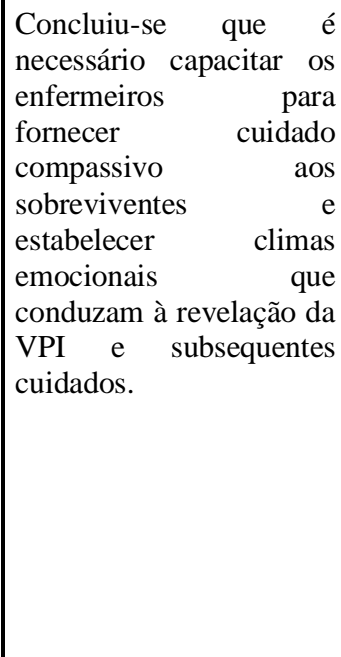 \\
\hline $\begin{array}{l}\text { Título: Atendimento de } \\
\text { enfermagem às mulheres } \\
\text { que sofrem violência } \\
\text { sexual. } \\
\text { Ano: } 2010 \\
\text { Periódico: Revista } \\
\text { Latino-Americana de } \\
\text { Enfermagem } \\
\text { Autores: Reis, M. J. D., } \\
\text { Lopes, M. H. B. D. M., } \\
\text { Higa, R., \& Bedone, A. } \\
\text { J. } \\
\text { País: Brasil. }\end{array}$ & $\begin{array}{lr}\text { Caracterizar } & \text { a } \\
\text { assistência } & \text { de } \\
\text { enfermagem } & \\
\text { prestada } & \text { pelo } \\
\text { enfermeiro } & \text { às } \\
\text { mulheres } & \text { que } \\
\text { sofreram } & \\
\text { violência } & \text { sexual, } \\
\text { atendidas } & \text { no } \\
\text { Hospital } & \text { da } \\
\text { Mulher } & - \\
\text { CAISM/Unicam } \\
\text { p. }\end{array}$ & $\begin{array}{l}\text { Estudo retrospectivo } \\
\text { e descritivo com } 146 \\
\text { fichas } \\
\text { atendimento } \\
\text { enfermagem de } \\
\text { mulheres, a } \\
\text { junho de } 2006 \text { a maio } \\
\text { de } 2007 \text {. }\end{array}$ & $\begin{array}{l}\text { Os resultados mostraram } \\
\text { que a maioria dos } \\
\text { atendimentos ocorreu } \\
\text { durante o período diurno, } \\
\text { houve coerência entre as } \\
\text { intervenções e os } \\
\text { diagnósticos } \\
\text { enfermagem de } \\
\text { identificados, e as } \\
\text { mulheres relataram que } \\
\text { receberam orientações de } \\
\text { acordo com o protocolo } \\
\text { do programa. }\end{array}$ & $\begin{array}{l}\text { Conclui-se que o } \\
\text { atendimento prestado } \\
\text { mostrou-se adequado e } \\
\text { com melhor qualidade no } \\
\text { plantão noturno. }\end{array}$ \\
\hline $\begin{array}{l}\text { Título: Characterization } \\
\text { of cases of violence } \\
\text { against women. } \\
\text { Ano: } 2020 \\
\text { Periódico: Revista de } \\
\text { Enfermagem da UFPE } \\
\text { on line } \\
\text { Autores: Ferreira, P. C., } \\
\text { Batista, V. C., Lino, I. G. } \\
\text { T., Marquete, V. F., } \\
\text { Pesce, G. B., \& Marcon, } \\
\text { S. S. } \\
\text { País: Brasil }\end{array}$ & $\begin{array}{lr}\text { Caracterizar } & \text { os } \\
\text { casos } & \text { de } \\
\text { violência } & \text { contra } \\
\text { a mulher. } & \end{array}$ & $\begin{array}{lr}\text { Trata-se de um } \\
\text { estudo quantitativo, } \\
\text { descritivo, ecológico, } \\
\text { de séries temporais. } \\
\text { Coletaram-se } & \text { os } \\
\text { dados do Sistema de } \\
\text { Informação } & \text { de } \\
\text { Agravos } & \text { e } \\
\text { Notificação extraídos } \\
\text { do Departamento de } \\
\text { Informática } & \text { do } \\
\text { Sistema Único de } \\
\text { Saúde. }\end{array}$ & $\begin{array}{l}\text { Revela-se que os casos } \\
\text { de violência contra a } \\
\text { mulher foram } \\
\text { predominantes na faixa } \\
\text { etária acima de } 20 \text { anos, } \\
\text { em vítimas com } \\
\text { escolaridade acima de } \\
\text { oito anos, raça/cor } \\
\text { branca, sendo o agressor, } \\
\text { na maioria das vezes o } \\
\text { cônjuge. Deram-se os } \\
\text { atos violentos, em geral, } \\
\text { na própria residência da } \\
\text { vítima por meio de } \\
\text { violência física } \\
\text { principalmente. }\end{array}$ & $\begin{array}{l}\text { Permite-se, } \\
\text { notificação, } \\
\text { realizada dela } \\
\text { completa e forma } \\
\text { conhecer o perfil da } \\
\text { violência, a identificação } \\
\text { dos fatores de risco e o } \\
\text { planejamento de } \\
\text { estratégias que visam à } \\
\text { prevenção, proteção e } \\
\text { assistência de qualidade } \\
\text { às vítimas de violência } \\
\text { contra a mulher. }\end{array}$ \\
\hline
\end{tabular}




\begin{tabular}{|c|c|c|c|c|}
\hline $\begin{array}{l}\text { Titulo: The duality of } \\
\text { suffering and trust: } \\
\text { abused } \\
\text { experiences of genen's } \\
\text { psychiatric care-an } \\
\text { interview study. } \\
\text { Ano: } 2014 \\
\text { Periódico: Journal of } \\
\text { clinical nursing. } \\
\text { Autores: Örmon, K., } \\
\text { Torstensson-Levander, } \\
\text { M., Sunnqvist, C., \& } \\
\text { Bahtsevani, C. } \\
\text { País: Suécia }\end{array}$ & $\begin{array}{l}\text { Elucidar como as } \\
\text { mulheres são } \\
\text { submetidas a } \\
\text { aspectos físicos, } \\
\text { emocionais } \\
\text { e/ou experiência } \\
\text { de abuso sexual } \\
\text { no atendimento } \\
\text { prestado em uma } \\
\text { clínica } \\
\text { psiquiátrica geral } \\
\text { após a } \\
\text { divulgação do } \\
\text { abuso. }\end{array}$ & $\begin{array}{l}\text { Pesquisa qualitativa, } \\
\text { desenvolvida com } \\
\text { nove mulheres que } \\
\text { receberam } \\
\text { tratamento } \\
\text { psiquiátrico. }\end{array}$ & $\begin{array}{l}\text { O tema geral emergente } \\
\text { das narrativas, mostrou } \\
\text { uma dualidade entre o } \\
\text { sofrimento e a confiança. } \\
\text { Estas mencionam que } \\
\text { são menosprezadas, mal } \\
\text { interpretadas e revelam a } \\
\text { maneira que vem sendo } \\
\text { cuidadas. }\end{array}$ & $\begin{array}{l}\text { Mulheres vítimas de } \\
\text { abuso são submetidas a } \\
\text { ambientes psiquiátricos } \\
\text { onde a equipe é dividida } \\
\text { em grupos daqueles que } \\
\text { acreditaram e apoiaram } \\
\text { os abusados mulheres e } \\
\text { aqueles que } \\
\text { consideraram as } \\
\text { experiências de abuso } \\
\text { como uma questão } \\
\text { secundária e focado no } \\
\text { transtorno mental. }\end{array}$ \\
\hline $\begin{array}{l}\text { Título: Physical and } \\
\text { sexual violence of the } \\
\text { intimate partner, } \\
\text { women's health and } \\
\text { children's behavioral } \\
\text { functioning: analysis of } \\
\text { the entry of a prospective } \\
\text { study. } \\
\text { Ano: } 2014 \\
\text { Periódico: Journal of } \\
\text { Clinical Nursing. } \\
\text { Autores: Symes, L., } \\
\text { Maddoux, J., McFarlane, } \\
\text { J., Nava, A., \& Gilroy, } \\
\text { H. } \\
\text { País: Estados Unidos }\end{array}$ & $\begin{array}{l}\text { Aumentar o } \\
\text { conhecimento da } \\
\text { parte íntima } \\
\text { física e sexual da } \\
\text { violência contra } \\
\text { as mulheres, seu } \\
\text { impacto na saúde } \\
\text { da mulher e das } \\
\text { crianças e o } \\
\text { funcionamento } \\
\text { comportamental. }\end{array}$ & $\begin{array}{l}\text { Estudo transversal, } \\
\text { usando dados de } \\
\text { linha de base de um } \\
\text { estudo prospectivo } \\
\text { de sete anos. }\end{array}$ & $\begin{array}{l}\text { Os maiores } \\
\text { escores de abuso sexual e } \\
\text { níveis mais altos de } \\
\text { abuso físico foram } \\
\text { associados com } \\
\text { maior ansiedade nas } \\
\text { mulheres. Níveis mais } \\
\text { altos de } \\
\text { abuso sexual foram } \\
\text { associados a maior } \\
\text { somatização materna e } \\
\text { pós-trauma } \\
\text { sintomas de transtorno de } \\
\text { estresse matemático. }\end{array}$ & $\begin{array}{l}\text { É necessário } \\
\text { compreender a questão } \\
\text { da violência sexual, visto } \\
\text { que à medida que } \\
\text { ganhamos uma maior } \\
\text { compreensão dessas } \\
\text { questões, seremos mais } \\
\text { capazes de desenvolver } \\
\text { políticas eficazes } \\
\text { e intervenções } \\
\text { terapêuticas para ajudar } \\
\text { mulheres vítimas de } \\
\text { abuso e seus filhos. }\end{array}$ \\
\hline
\end{tabular}

Fonte: Machado \& Freitag (2020).

Observa-se no quadro acima que dos nove estudos selecionados, cinco foram desenvolvidos no Brasil, dois nos Estados Unidos e um na Suécia. Em relação ao percurso metodológico, seis utilizaram abordagem qualitativa e três foi uma pesquisa quantitativa. Os resultados e conclusões apontam para a necessidade de qualificação profissional para o cuidado das mulheres vítimas de violência sexual.

\section{Discussão}

A partir dos estudos apresentado acima, elaborou-se um tema: O cuidado de enfermagem a mulher vítima de violência sexual.

\section{1 $O$ cuidado de enfermagem a mulher vítima de violência sexual}

A violência sexual é a situação em que a vítima se sente obrigada, forçada ou até mesmo ameaçada a praticar atos sexuais contra sua vontade. Diante disso é comum o crime ser cometido pelo próprio marido, namorado ou companheiro (Brasil, 2012). Os tipos de violência sexual mais comum são: o estupro dentro do casamento, namoro ou companheiro; estupro cometido por estranhos; estupro coletivo, o assédio sexual, inclusive exigência de sexo como pagamento de favores; abuso sexual de pessoas mental ou fisicamente incapazes; negação do direito de usar anticoncepcionais ou de adotar medidas de proteção contra doenças sexualmente transmissíveis; aborto forçado; e exames obrigatórios de virgindade, prostituição forçada e tráfico com fins de exploração sexual (Brasil, 2002). Neste contexto, faz-se necessário um cuidado sensível, compreensivo e acolhedor. 
$\mathrm{O}$ acolhimento e o cuidado de enfermagem são muito além das diferentes formas que os profissionais veem a violência, em sua maioria, leem e constroem a realidade a partir do preconceito ou apenas de seus referenciais teóricos, enquanto outros o fazem a partir da experiência reflexiva (Örmon et al., 2014). Neste contexto, faz-se necessário que o enfermeiro possa, a partir do cuidado reflexivo, compreender todo o processo que evolve a violência sexual, a fim de ser apoio a vítima, dirimindo suas dúvidas e a auxiliando da melhor maneira possível.

Observa-se que o acolhimento de enfermagem é mais que afinidades que se formam entre a vítima e os profissionais no cuidado à saúde, não se tratam de uma simples semelhança de prestação de serviço, o acolhimento sugere uma relação humanizada, de escuta individualizada. O cuidado de enfermagem tem um significado especial e é representado não só por procedimentos elaborados e sofisticados, mas também atitudes de sinceridade, como um sorriso, um toque, um abraço (Pianussi, 2019).

Neste contexto, o estudo que objetivou identificar a percepção das vítimas de violência sexual em relação ao acolhimento prestado pela equipe de enfermagem no pronto atendimento de um hospital de referência no Brasil, os resultados mostraram que o cuidado prestado vai além de procedimentos técnicos, acontece um cuidado individualizado com foco às necessidades de cada mulher. Ainda, a postura dos profissionais proporciona sentimentos positivos como segurança e tranquilidade (Batistetti; Lima \& Souza, 2020).

Ainda, nessa premissa, Pianussi (2019) menciona que a importância do cuidar consiste em adicionar gestos simples aos passos duros e frios das técnicas. A essência dessa atitude não é apenas o cuidar do aspecto frágil do ser humano, mas cuidar olhando, ouvindo, conversando, tocando e promovendo a saúde.

Diante do exposto, reflete-se sobre a importância do acolhimento e de um cuidado individualizado, com ênfase nas necessidades de cada mulher vítima de violência sexual, visto que desta maneira, estas sentem-se mais seguras e assim facilita a abertura do diálogo entre enfermeiro e a vítima. Quando o cuidado se efetiva facilita a abertura do diálogo entre enfermeiro e a vítima possibilitando a compreensão da vítima, ouvi-la com sensibilidade e solidariedade, o que caracteriza a qualidade do cuidado. Sendo assim, o acolhimento no trabalho de enfermagem é no sentido de realizar atitudes humanizadoras que se revelam no ato de receber, escutar e tratar da sua dor.

A Secretaria de Políticas para as Mulheres, o Ministério da Saúde e o Ministério da Justiça trabalham em conjunto o desenvolvimento de ações que possibilitem estratégias de prevenção, acolhimento, atendimento e proteção às pessoas em situação de violência. Ao mesmo tempo, criam estratégias para garantir a responsabilização e o combate à impunidade de autores (as) de agressão a serem implantadas e implementadas nas unidades da federação. Reunir essas iniciativas para a unificação de procedimentos é possível quando a articulação e atuação governamental expressam o desejo de possibilitar à pessoa em situação de violência sexual um atendimento digno, humanizado e resolutivo, buscando evitar revitalizações e torná-lo mais ágil e com menos exposição da pessoa que sofreu a violência. (Brasil, 2015).

Em relação ao acolhimento da equipe de enfermagem às vítimas de violência sexual, a literatura aponta fragilidades no tratamento com essas vítimas de abuso, pois estas sofrem algumas vezes uma exposição desnecessária por profissionais os quais não tem conhecimento prévio necessário (Jesus et al., 2019).

Grande parte dessas mulheres sofre diante de profissionais, que tem uma abordagem de "culpa da vítima" quando surgem questões sobre por que uma mulher pode escolher permanecer em um relacionamento dessa maneira. Uma das principais razões que as mulheres mencionam para não divulgar a violência é pela vergonha, pois muitas vezes culpam um sobrevivente pela violência, dizendo que "pediu" ou "trouxe para si mesma" em função de características de estereótipos, bem como a forma como se vestem, arrumam o cabelo, maquiagem e entre outras (Canosa, 2019; Gonçalves, 2020).

É importante destacar que as vítimas de violência esperam dos profissionais de saúde um cuidado eficaz, no entanto, lhes são impostas muitas responsabilidades, sentem o preconceito, ainda as fazem suposições, promessas ou perguntas 
desnecessárias, fazendo com que sintam medo e fragilidade, sem uma orientação cuidadosa e segura. Todavia, no contexto da violência sexual contra a mulher faz-se necessário uma assistência de enfermagem que ofereça um ambiente com privacidade, livre de preconceitos, com uma escuta sensível, ofertando um cuidado de uma forma integral, bem como a necessidade de um protocolo específico para estes casos.

Em uma pesquisa realizada com enfermeiras que atuam na Unidade Básica de Saúde do município de Campina Grande no Brasil, Baptista et al., (2015) menciona que durante o desenvolvimento do estudo, observou-se ausência de protocolo direcionado para atendimento das vítimas de violência sexual. Esse fato demonstra o despreparo profissional, criando um ambiente de insegurança, principalmente na abordagem da vítima, no tratamento e no manejo adequado dos casos.

Diante disso, faz-se necessário que o enfermeiro aprofunde o conhecimento de modo a promover a qualificação da equipe para o enfrentamento da violência sexual contra as mulheres (Mota \& Aguiar, 2020), compreendendo o contexto e auxiliando esta da melhor maneira possível para a resolução e superação do ocorrido.

Nesta premissa, Ribeiro, Gaspar \& Vieira et al., (2016), desenvolveram um estudo com o objetivo de descrever a experiência obtida no atendimento de acadêmicos de Enfermagem à mulheres vítimas de violência doméstica. Os pesquisadores identificaram que no atendimento a esta mulher, a paciente apenas relatou o caso de violência física, sexual e psicológica quando o profissional responsável pelo atendimento demonstrou empatia e favoreceu o vínculo, vencendo a barreira do medo e constrangimento que envolve grande parte desses casos.

Observa-se que o cuidado neste contexto, foi humanizado, com empatia. Rosselò (2009) do discorrer sobre o cuidado, afirma que cuidar de alguém é estar com ele, e mais que isso, é ser-com-ele, andar lado a lado e no ritmo de seus passos. Tratase de uma ação de passividade, é ser receptivo à pessoa vulnerável, é responder as suas necessidades, velando por sua integridade e a unidade de seu ser.

Este cuidado é essencial, visto que a violência sexual contra a mulher causa um grande impacto na vida da mesma, trazendo traumas tanto físicos, psicológicos e mentais. Neste cenário, o enfermeiro poderá realizar um cuidado multidisciplinar, assim, a vítima receberá cuidados que contribuem diretamente com o tratamento, sobretudo na amenização da dor moral e emocional, a que foi submetida (Santos; Dias \& Carvalho, 2019), dentre outras consequências.

As consequências às mulheres que vivenciam a violência sexual vão desde a contaminação com as Infecções Sexualmente Transmissíveis (IST), gravidez indesejada, aborto inseguro, transtornos psiquiátricos, como Transtorno de Estresse Pós-Traumático (TEPT), transtorno de humor, disfunção sexual, depressão, síndrome do pânico, uso de substâncias psicoativas, e até o suicídio (Delziovo et al., 2017).

$\mathrm{O}$ impacto d violência sexual contra a mulher ultrapassa o aspecto físico, provocando o sofrimento psíquico e emocional que vem refletindo negativamente no desempenho das atividades rotineiras dessas vítimas como consequências ao medo de ter contato com pessoas desconhecidas, evitando outros relacionamentos afetivos, e sexuais, o medo de passar pelo estupro novamente, cometendo com que essas vítimas dependessem de outras pessoas para atividades cotidianas (Trigueiro et al., 2017).

Neste contexto, faz-se necessário um acompanhamento especializado no cuidado à saúde mental das mulheres vítimas de violência sexual, visto que ocorre uma mudança drástica no comportamento. Muitas, desenvolvem depressão, ansiedade, isolamento social, medo, traumas, preocupação, insônia, síndrome de pânico, muitas cometem suicídio, além do uso de álcool e drogas, iniciando assim o uso de medicamentos ansiolíticos. Diante disso, percebe-se a importância do cuidado dos profissionais de saúde, identificando os casos precocemente, por meio de um acolhimento humanizado com ênfase na integralidade (Alves et al., 2020).

Dessa maneira, observa-se que a dificuldade da situação que envolve a violência sexual, requer não só o atendimento no serviço de referência, mas também depende de uma rede de serviços de saúde. Os serviços especializados devem contar 
com equipes multiprofissionais atuando na lógica interdisciplinar, com objetivo a resgatar a autoestima e o fortalecimento das mulheres (Trigueiro et al., 2017).

Neste contexto, os estudos mostraram que ao trabalhar como enfermeiro diante dessas vítimas sobreviventes de violência de abuso sexual, é importante os profissionais fornecerem assistência, compreendendo o impacto psicológico em torno dessa atrocidade, que envolve poder e controle, assim sendo, capacitados cientificamente, mas, além disso, psicologicamente, poderão desenvolver o cuidado primordial, como a oferta da pílula do dia seguinte, coleta de materiais para efetivação do exame de HIV ou doenças sexualmente transmissíveis, dentre outros meios para preservação da sua vida (Hawley \& Barker, 2012).

Desde 1998, o Ministério da Saúde do Brasil (MS) padronizou o atendimento multidisciplinar para as vítimas de violência sexual por meio de Norma Técnica. $\mathrm{O}$ atendimento emergencial, nas primeiras 72 horas após a violência, tem por objetivo acolhimento e administração de anticoncepção de emergência e a profilaxia para as ISTs, doenças virais e bacterianas (Machado et al., 2015).

O Ministério da saúde preconiza a garantia do atendimento à mulher vítima de violência sexual em serviços de saúde, por ser considerado um sério problema de saúde pública e por ser uma das principais causas de morbidade e mortalidade feminina. Tal atendimento tem a finalidade de diminuir os agravos gerados por esse tipo de violência como, prevenção de doenças sexualmente transmissíveis e à gravidez indesejada. Nos serviços de saúde, a mulher violentada sexualmente necessita de acolhimento, fator fundamental para a humanização da assistência à saúde é essencial para que se estabeleça um relacionamento de forma adequada entre o profissional e a paciente (Petrício, 2019)

O mesmo autor menciona que o atendimento integral preconizado pelo Ministério da Saúde é desrespeitado devido aos ambientes ambulatoriais inadequados e aos profissionais incapacitados para atender às mulheres segundo as normas. Predomina a assistência medicalizada, tradicional e fragmentada, que valoriza o modelo hegemônico biomédico e despreza ações de caráter preventivo e de promoção à saúde. As mulheres desconhecem os seus direitos, e sofrem reflexo de uma sociedade que ainda a culpa pela agressão sofrida (Petrício, 2019).

Apesar de todos os avanços nas políticas de saúde e leis de proteção às vítimas, a violência é um fenômeno frequente no dia a dia desta população e seu enfrentamento ainda é um desafio. Acredita-se que a falta de notificação por meio das mulheres vítimas, deve-se ao medo, à falta de confiança, bem como o preenchimento inadequado dos campos da ficha de notificação, tal fato, pode oportunizar a subnotificação de casos e comprometer a avaliação real das variáveis (Ferreira et al., 2020).

Em relação a notificação, os dados coletados devem ser rigorosamente anotados no prontuário e devem servir de guia para todos os membros da equipe multiprofissional, para evitar que a mulher reconte a história dessa agressão, para logo serem registradas em fichas unificadas e específicas com espaços para as observações de todas as categorias profissionais. O primeiro acolhimento da mulher ocorre na emergência, e este exige conhecimento teórico/prático por parte dos profissionais de enfermagem, o qual deve ser composto por entrevista, exame físico e ginecológico, coleta de amostras para diagnóstico de infecções genitais, coleta de material para identificação do provável autor da agressão e o preenchimento da ficha de notificação da Violência sexual (Bezerra et al., 2018)

Nessa premissa, além da lacuna no relato da mulher ao falar sobre o ocorrido, também existe uma falha no atendimento profissional, visto que estes, em sua maioria, não têm capacitação para este cuidado. Sendo assim, faz-se necessário o aperfeiçoamento e a qualificação dos profissionais de saúde para identificar as inquietas faces da violência que podem estar presentes em seus atendimentos, bem como a adequada notificação dos casos, a qual é eficaz para o enfrentamento desta problemática, pois permite conhecer o perfil da violência, visando o planejamento da assistência integral às vítimas. 
Em relação a legislação, Bezerra et al., (2018), mencionam um avanço na esfera nacional de enfrentamento da temática. A Lei no ${ }^{\circ} 12.845 / 2013$ prevê a obrigatoriedade do atendimento integral a pessoas em situação de VS nos hospitais do SUS. Dessa forma, todos os serviços da rede hospitalar tornam-se responsáveis por essa atenção.

Com bases nos estudos, observa-se que nos últimos anos aconteceram avanços nas ações voltadas para ao enfrentamento aos diferentes tipos de violência contra as mulheres no Brasil, porém, ainda existem casos que não são relatados pelas vítimas e ainda existe o agravante da subnotificação nos serviços de saúde, seja por desconhecimento dos instrumentos legais ou por insegurança.

Contudo/apesar de, a literatura aponta a resiliência destas mulheres perante a violência sexual, quando o atendimento da enfermagem é baseado no cuidado integral e humanizado. Neste contexto, estudo que objetivou conhecer o processo de resiliência em mulheres vítimas de violência sexual, os resultados mostraram que o sentimento de cuidado e responsabilidade promovem uma mobilização interna, a qual proporciona o início de um processo de resiliência. Assim, a escuta acolhedora, sem julgamentos, tornou possível a representação do trauma vivido pelas mulheres. Ainda, destaca-se a espiritualidade, baseada na religação e na reativação da fé, as quais forneceram subsídios para acreditar que sobreviver é mais relevante do que ser vítima (Fornari \& Labronici, 2018)

Barlach et al., (2008) mencionam que resiliência se refere à capacidade de o ser humano apresentar-se de forma positiva frente às dificuldades, mediante observação das formas positivas de conduta de pessoas que vivenciaram fatores negativos. É ter a capacidade de dar a volta por cima, superando adversidades e transformando experiências negativas em aprendizado, diante de situações traumáticas individuais, como o abuso sexual, ou coletivo.

Podemos compreender que a resiliência só pode ser pensada a partir do momento em que o ser humano vivencia em sua trajetória de vida uma experiência traumática que exige a tomada de decisão, no sentido de querer enfrentá-la e seguir adiante. A experiência traumática neste estudo é a violência sexual sofrida pelas mulheres, um fenômeno que pode deixar marcas visíveis e invisíveis, causando, dor e sofrimento (Labronici et al., 2010).

A violência sexual é uma experiência traumática, pela qual a mulher poderá entregar-se ao sofrimento, todavia, ao decidirem enfrentar o trauma para retomar a compreensão da realidade, exercitam a resiliência. Estudo observou que as vítimas perceberam a necessidade de narrar à experiência vivida para outras pessoas, além de compartilharem o trauma vivido com os familiares, além disso, buscam os serviços integrantes da rede de atenção, bem como a importância e o fortalecimento da espiritualidade após o trauma, reativando a sua fé espiritual. (Fornari \& Labronici, 2018)

A promoção de um atendimento integral pode ser concretizada mediante o conhecimento da enfermeira na atenção às mulheres vítimas de violência sexual, através da aplicação adequada dos protocolos clínicos, principalmente, por meio de ações de cuidado significativo. As ações de cuidado expressivo estão relacionadas à subjetividade, e a enfermeira, ao desenvolvê-las, deve ter postura ética, acolhedora, com escuta ativa e atentiva (Labronici, 2012), visto que essa atitude pode facilitar a expressão dessas mulheres em relação aos seus sentimentos de angústia, medo e perspectivas futuras.

Diante do exposto, observa-se a necessidade de disciplinas na graduação que abordem o tema violência contra a mulher, bem como o debate sobre resiliência, visto que o enfermeiro atuará em serviços que prestam atendimento a tais vítimas. É pertinente, em razão de formar profissionais qualificados para o manejo das situações ao cuidar dessas mulheres, buscam conhecer melhor o outro, acolher, estabelecer uma relação de cuidado complementar a rede de apoio, com uma postura de abertura, podendo realizar uma escuta ativa, de atitude como uma forma de cuidar e estimular o trajeto da resiliência.

Symes et al., (2014), menciona que as mulheres que experienciam a violência física e sexual corre maior risco de comprometer a saúde do que mulheres que sofrem apenas violência física. Mulheres vítimas de violência sexual têm maior ansiedade, somatização materna, trauma e estresse. Neste sentido, os autores concluíram os profissionais de saúde, em especial 
a enfermagem que precisa ter máxima compreensão dessas questões, visto que assim, serão capazes de desenvolver políticas eficazes e intervir terapeuticamente para ajudar mulheres vítimas de abuso sexual.

Nesta premissa, pode-se dizer que as mulheres que sofrem violência sexual têm sentimentos como: ansiedade, estresse, traumas, entre outros sentimentos, contudo, há momentos em que os enfermeiros podem sentir-se despreparados, impotentes com o atendimento às vítimas de violência sexuais, principalmente ao se depararem com a falta de acesso, sensibilidade, acolhimento e humanização por parte de outros profissionais de saúde, bem como pela desestrutura emocional e pela ausência de suporte para solucionar casos de uma maior gravidade.

Assim sendo a capacitação dos profissionais reflete absolutamente na percepção que eles têm em relação à assistência de enfermagem prestada, o que comprovou dentro dessa categoria duas classes de respostas: na primeira, os profissionais que se sentem capacitadas e, mesmo com os treinamentos e capacitação, relatam a necessidade de sempre estarem buscando mais conhecimento como a maneira de melhorar o atendimento às vítimas de violência, tornando-o mais eficaz e eficiente. E a segunda classe de respostas está relacionada à percepção dos enfermeiros que se dizem não estar capacitados, evidenciando a falta de manejo prático e ausência de outros profissionais de saúde para dar suporte e segmento ao atendimento (Feltrin; Toso \& Cheffer, 2019).

A violência contra a mulher tem sido reconhecida como um problema de saúde pública prioritário, pois ameaça sua saúde física e mental e pelas consequências familiares, sociais e econômicas que geram. Contudo, a enfermagem tem papel fundamental no cuidado a mulher vítima de violência, especialmente o abuso sexual, ainda, observa-se que os profissionais têm diversas maneiras de abordagem para interpretar este fenômeno e elaborar os cuidados a serem prestados. Os resultados ainda mostraram que nenhuma mulher quer ser violada, humilhada e degradada, e por isso pode deixar de ser negada, de ser sujeito de direitos, de reconstruir-se após este sofrimento, superando o abandono de si para encontrar os caminhos da dignidade e da liberdade no encontro consigo mesmo, no cuidado de si, como protagonista da própria existência (Ballén, 2015).

Nesta perspectiva pode-se observar que ainda existem obstáculos para efetivação das políticas na assistência às mulheres vítimas de violência sexual, e, os profissionais de saúde necessitam de capacitação, bem como um ambiente adequado para assisti-las. Existe uma vasta produção científica acerca da percepção da mulher sobre o atendimento de violência sexual relacionando a saúde pública, que por se tratar de um tema com carga emocional, incluído a hospitalização e a fragilidade da vítima, faz-se necessário levar em conta a efetividade do cuidado.

Em relação ao cuidado da enfermagem a mulher vítima de violência, estudo de Reis et al., (2010) que teve como objetivo caracterizar a assistência de enfermagem prestada às mulheres que sofreram violência sexual, atendidas no Hospital da Mulher, os resultados mostraram que a maioria dos atendimentos ocorreu durante o período diurno, e as intervenções e os diagnósticos de enfermagem identificados foram coerentes, e ainda, relataram que receberam orientações de acordo com o protocolo do programa. Observaram ainda que, as consultas noturnas eram mais longas esta conheciam os riscos de saúde, decorrentes da violência sexual, compreendendo a necessidade do uso do antirretrovirais e a finalidade das sorologias. Assim, concluíram que o atendimento noturno mostrou-se mais adequado e com melhor qualidade.

Compreender o complexo mundo da mulher que sofreu violência sexual é uma necessidade urgente, visto que estimativas globais indicam que, aproximadamente, uma em cada três mulheres (35\%) em todo o mundo sofreram violência física ou sexual por parte do parceiro ou de terceiros durante a vida (OMS, 2017). No Brasil, segundo dados do Anuário Brasileiro de Segurança Pública, registrou-se um estupro a cada 11 minutos em 2015. Ademais, há o agravante das subnotificações dos casos, que não entram nas estatísticas. Frente a essa deplorável realidade, percebeu-se a necessidade de criar protocolos, leis e normas técnicas que assegurassem uma assistência integral às vítimas de violência sexual.

Ainda assim, sabe-se que não há um regimento padrão de âmbito nacional para proceder com o atendimento em saúde das vítimas de violência sexual, o que varia bastante de estado para estado e, até mesmo, de hospital para hospital. Para isso, 
em 2012, o Ministério da Saúde atualizou a Norma Técnica de Prevenção e Tratamento dos Agravos Resultantes da Violência Sexual contra Mulheres e Adolescentes no intuito de auxiliar profissionais de saúde na organização de serviços e no desenvolvimento de uma atuação eficaz e qualificada nos casos de violência, bem como garantir o exercício pleno dos direitos humanos das mulheres, base de uma saúde pública de fato universal, integral e equânime, levando em consideração os danos emocionais que o fato causa (Dumont et al., 2019)

Considerando a preocupação com o estado emocional, os serviços norte-americanos de cuidado às vítimas de violência sexual utilizam um protocolo de atendimento conhecido como Sexual Assault Nurse Examiner (SANE), projetado para atender às necessidades imediatas e prevenção de implicações. Esse protocolo baseia-se no cuidado integral, visando cinco componentes: cuidado físico, prevenção, de gravidez; triagem de DST; atendimento psicológico, e cuidado legal, para obtenção de provas forenses (Barros et al., 2015)

Partindo dessas evidências citadas acima o protocolo de enfermagem aliado a empatia profissional, tem proporcionado à vítima um atendimento integral e humanizado e à enfermagem, maior autonomia na sua área de atuação, favorecendo o trabalho colaborativo e interativo com a equipe multidisciplinar, que dispõe de protocolos multidisciplinares individuais e de equipe treinada, visando prevenir a gravidez indesejada, as doenças sexualmente transmissíveis (DST), incluindo o vírus da imunodeficiência humana (HIV), promovendo a recuperação física, psicológica e social da mulher agredida sexualmente. Além do mais realizando intervenções de enfermagem, de acordo com os diagnósticos de enfermagem identificados.

Diante do contexto da violência sexual contra a mulher, ainda no ano de 1992, enfermeiras norte-americanas especializadas em Sexual Assault Nurse Examiners (SANE) fundaram a Internacional Association Forensic Nursing (IAFN), com o objetivo de aplicar o conceito, as estratégias e as intervenções às vítimas de violência e aos perpetradores, na prática profissional de enfermagem (IAFN, 2017a). Três anos após, em 1995, a American Nurses Association (ANA) reconheceu a Enfermagem Forense como uma das mais novas especialidades na classe profissional dos enfermeiros, incluindo subespecialidades de Enfermagem Forense (IAFN, 2017a).

No Brasil, essa especialidade foi adotada somente no ano de 2011, através da Resolução de número 389 de 18 de outubro do Conselho Federal de Enfermagem (COFEN), tendo sua área de abrangência listadas nesta mesma resolução, o que torna o enfermeiro apto para atuar no âmbito da violência. No ano de 2017, o COFEN publicou a resolução de número 556, com o objetivo de regulamentar a atividade do Enfermeiro Forense no Brasil. A resolução apresenta oito áreas de atuação e destaca que uma de suas competências gerais é acolher a vítima de violência sexual, traumas e outras formas de violência, proceder com a avaliação das vítimas e contribuir com o sistema judicial. Em concordância com a Associação Brasileira de Enfermagem Forense (ABEFORENSE), os Enfermeiros Forenses são profissionais capacitados para identificar o campo de violência, estabelecer diagnósticos contextualizados, executar medidas preventivas e terapêuticas legalmente suportadas, avaliar resultados e ganhos para a saúde, no âmbito do trauma e violência. (Soares et al., 2019)

Com base nos estudos supracitados, observa-se que a especialidade forense relacionada à Enfermagem é de extrema importância para a saúde da mulher, uma vez que no Brasil, o número de casos de violência ligado ao gênero feminino está em constante crescimento na nossa atualidade, por este motivo, seria interessante começar esta propagação de conhecimento na educação continuada de profissionais de enfermagem e na área acadêmica, inserindo conteúdos que englobem a atuação do Enfermeiro na área forense.

A violência contra a mulher é um problema de saúde pública, e, existe uma lacuna em relação ao acolhimento/cuidado a estas mulheres, seja pela falta de a utilização de um protocolo no atendimento, ou pelo despreparo profissional que ainda vê a vítima como a causadora da violência, justificando que o estigma está também entre aqueles que precisam acolher e cuidar. 


\section{Considerações Finais}

Ao responder o objetivo do estudo, observou-se que o cuidado de enfermagem às vítimas da violência sexual, raramente é baseado na empatia. Existem muitos julgamentos aliado ao despreparo profissional que desconhecem e não utilizam um protocolo de atendimento e escuta humanizada.

Apesar das leis e normas técnicas criadas, a efetividade do cuidado ainda é um desafio, contudo, observou-se a resiliência das mulheres, ao elencarem seus objetivos futuros e decidirem viver e superar o trauma causado pela violência, ora acometida. Tal resiliência deve-se, seja pelos filhos, seja pela religiosidade, e, ou por elas mesmas.

Espera-se que este estudo traga contribuições para a enfermagem, a fim de repensar suas ações de cuidado neste contexto, bem como refletir sobre a importância da capacitação profissional e da utilização de protocolos efetivos que comportem uma rede de cuidados a fim de que esta mulher fique minimamente exposta.

O estudo limita-se pela lacuna na produção científica que aborde os temas violência sexual e cuidado de enfermagem, bem como a busca em algumas das bases de dados. Neste sentido, sugere-se que os cursos de graduação em enfermagem construam disciplinas que aborde tal temática a fim de que possam formar profissionais mais atentos e empáticos neste contexto de cuidado. Ainda, a construção de projetos de pesquisa, ensino e extensão poderão instigar gestores e profissionais a adquirir abordagens eficazes no cuidado a mulher vítima de violência sexual.

\section{Referências}

Alves, R. S. S., da Silva, E. R., Soares, I. L., Fagundes, G. R. S., de Lima Oliveira, B., de Almeida, L. F., \& da Silva Marques, V. G. P. (2020). "Pode gritar, ninguém vai acreditar em você": A saúde mental de mulheres vítimas de violência sexual. Research, Society and Development, 9 (11), e1509119652e1509119652, 1-18

Araújo, R. J. G. D., Mendes, M. D. B. B. L., Castro, T. M., Moreira Júnior, M. T., Araújo, A. B. L., \& Pacheco, L. M. (2011). Analysis of facial trauma affecting women victims of domestic violence. Revista Facultad de Odontología, 31 (1-2), 102-111.

Ballén, M. N. (2015). Cuidar de mulheres agredidas na adversidade. Índice de enfermagem, 24 (1-2), 62-66.

Baptista, R. S., de Melo Chaves, O. B. B., de França, I. S. X., de Sousa, F. S., de Oliveira, M. G., \& da Silva Leite, C. C. (2015). Violência sexual contra mulheres: a prática de enfermeiros. Revista da Rede de Enfermagem do Nordeste - RENE, 16 (2), 210-217.

Barlach, L., Limongi-França, A. C., \& Malvezzi, S. (2008). O conceito de resiliência aplicado ao trabalho nas organizações. Interamerican Journal of Psychology. 42(1), 101-112.

Barros, L. D. A. et al. (2015). Vivência de (des)acolhimento por mulheres vítimas de estupro que buscam os serviços de saúde. Revista da Escola de Enfermagem da USP, 49 (2), 0193-0200.

Batistetti, L. T. Lima, M. C. D. D., \& Souza, S. R. R. K. (2020). A percepção da vítima de violência sexual quanto ao acolhimento em um hospital de referência no Paraná. Revista de Pesquisa: Cuidado é Fundamental Online, (12), 168-174.

Bezerra, J. D, F. (2018). O atendimento da mulher em situação de violência sexual em um serviço de referência. Tese apresentada à Faculdade de Ciências Médicas da Universidade Estadual de Campinas como parte dos requisitos exigidos para a obtenção do Título de Doutora em Saúde Coletiva, na área de Ciências Sociais em Saúde. Campinas, SP, 178p.

Brasil. (1988). Constituição da República Federativa do Brasil de 1988. http://www.planalto.gov.br/ccivil_03/constituicao/constituicao.htm.

Brasil. (2013). Decreto no 7.958, de 13 de março de 2013.http://www.planalto.gov.br/ccivil_03/_ato2011-2014/2013/decreto/d7958.htm.

Brasil. (2015). Norma técnica atenção humanizada às pessoas em situação de violência sexual com registro de informações e coleta de vestígios. https://bvsms.saude.gov.br/bvs/publicacoes/atencao_humanizada_pessoas_violencia_sexual_norma_tecnica.pdf.

Brasil. (2012). Ministério da Saúde. Prevenção e tratamento dos agravos resultantes da violência sexual contra mulheres e adolescentes: norma técnica. $3^{\text {a }}$ edição. Brasília, DF. https://bvsms.saude.gov.br/bvs/ publicacoes/prevencao_agravo_violencia_sexual_mulheres_3ed.pdf.

Brasil. (2002). Ministério da Saúde. Violência Intrafamiliar: orientações para a Prática em Serviço. Brasília, DF. http://www.campogrande.ms.gov.br/semu/downloads/cartilha-violencia-intrafamiliar-orientacoes-para-a-pratica-em-servico/.

Brasil. (2015). Secretaria de Políticas para as Mulheres. Atenção humanizada às pessoas em situação de violência sexual com registro de informações e coleta de vestígios: norma técnica. https://bvsms.saude.gov.br/bvs/publicacoes/atencao_humanizada_pessoas_violencia_sexual_norma_tecnica.pdf.

Canosa, L. (2019). Antes do tiro o tapa. Cadernos de Psicanálise, 35(1), 12-15. 
Centro Estadual de Vigilância em Saúde (CEVS). (2019). Tipologia da Violência. https://www.cevs.rs.gov.br/tipologia-daviolencia\#: :text=A\%20Organiza\%C3\%A7\%C3\%A3o\%20Mundial\%20da\%20Sa\%C3\%BAde,\%2C\%20organiza\%C3\%A7\%C3\%B5es\%20terroristas\%2C\%2 $0 \mathrm{mil} \% \mathrm{C} 3 \%$ ADcias).

Dahlberg. L. Krug. E. (2007). Violência: um problema global de saúde pública. Ciência \& Saúde Coletiva, 11 (Sup), $1163-1178$.

Delziovo, C. R., Bolsoni, C. C., Nazário, N. O., \& Coelho, E. B. S. (2017). Características dos casos de violência sexual contra mulheres adolescentes e adultas notificados pelos serviços públicos de saúde em Santa Catarina. Brasil. Cadernos de Saúde Pública, (33)e00002716, 1-13.

Dumont, L. S., Abrahão, A. M. B., Manata, I. C., Pereira, B. D., de Souza Alves, P. E., \& Nascimento, D. B. (2019). Atendimen to às mulheres vítimas de violência sexual: realidade e desafios. http://periodicos.unievangelica.edu.br/index.php/educacaoemsaude/article/view/3786/2630.

Feltrin, B., Toso, L., \& Cheffer, M. (2019). Ser enfermeiro e o cuidado a mulheres vítimas de violência doméstica: situações vivenciadas. Revista Varia Scientia, 5(2), 143-152.

Ferreira, P. C., Batista, V. C., Lino, I. G. T., Marquete, V. F., Pesce, G. B., \& Marcon, S. S. (2020). Caracterização dos casos de violência contra mulheres. Revista de enfermagem - UFPE on line, 4(e243993), 1-6.

Freire, S. M. L. (2018). Aspectos da enfermagem forense na assistência as mulheres vítimas de violência sexual. http://www.repositorio.ufc.br/bitstream/riufc/38382/1/2018_tcc_smlfreire.pdf.

Fornari, L. F. Labronici, L. M. (2018). O processo de resiliência em mulheres vítimas de violência sexual: uma possibilidade de cuidado. Cogitare Enfermagem, 23(1:e52081), 1-8.

Gonçalves, C. R. (2020). Responsabilidade civil. $19^{\mathrm{a}}$ edição. São Paulo, Saraiva Educação. https://books.google.com.br/books?hl=ptBR\&lr=\&id=MbjEDwAAQBAJ\&oi=fnd\&pg=PT1512\&dq=\%22culpa+da+v\%C3\% ADtima\%22+viol\%C3\%AAncia+sexual+mulher+em fermagem+cuidado \&ots=fI68qP8EPT\&sig=VoYJJ1A5SSk_WqhEW2pk7IwKeFo\#v=onepage \&q\&f=false.

Hawley, D. A., Barker, A. C. H. (2012). Survivors of intimate partner violence: implications for nursing care. Critical Care Nursing Clinics, 24(1). 27-39.

International Association of Forensic Nurses (IAFN). (2017). History of the association, Silver Spring, Maryland. https://www.forensicnurses.org/page/AboutUS?

Jesus, S. S., da Silva, S. B., de Andrade Aoyama, E., \& Lemos, L. R. (2019). Acolhimento de enfermagem às pessoas vítimas de violência sexual. Revista Brasileira Interdisciplinar de Saúde, 1(4), 37-43.

Labronici, L. M., Trigueiro, T. H., Raimondo, M. L., Fegadoli, D., \& da Silva Batista, J. M. (2010). A redescoberta da maternidade por mulheres vítimas de violência doméstica: uma possibilidade existencial. Cogitare enfermagem, 15(3), 474-479.

Labronici, L. M. (2012). Processo de resiliência nas mulheres vítimas de violência doméstica: um olhar fenomenológico. Texto \& contexto-enfermagem, 21(3), $625-632$.

Machado, C. L., Fernandes, A. M. D. S., Osis, M. J. D., \& Makuch, M. Y. (2015). Gravidez após violência sexual: vivências de mulheres em busca da interrupção legal. Cadernos de Saúde Pública, 31(2), 345-356.

Mendes, K. D. S., Silveira, R. C. D. C. P., \& Galvão, C. M. (2008). Revisão integrativa: método de pesquisa para a incorporação de evidências na saúde e na enfermagem. Texto \& contexto-enfermagem, 17(4), 758-764.

Michaelis. (2008). Dicionário Brasileiro da Língua Portuguesa. https://michaelis.uol.com.br/moderno-portugues/busca/portuguesbrasileiro/viol\%C3\%AAncia/.

Modena, M. R. (2016). Conceitos e formas de violência. Caxias do Sul, RS: Educs. https://www.ucs.br/site/midia/arquivos/ebook-conceitos-formas_2.pdf.

Mota, J. A., \& Aguiar, R. S. (2020). Percepções de enfermeiros da atenção primária no atendimento às mulheres vítimas de violência sexual. Nursing (Säo Paulo), 23(262), 3848-3651.

Organização Mundial da Saúde. (2002). Relatório mundial sobre violência e saúde. Organização Mundial da Saúde. Genebra. http://portaldeboaspraticas.iff.fiocruz.br/wp-content/uploads/2019/04/14142032-relatorio-mundial-sobre-violencia-e-saude.pdf.

Organização Pan-Americana da Saúde. (2017). Violência contra as mulheres. Folha informativa, 2017. https://www.paho.org/bra/index.php?option $=$ com_content $\&$ view=article $\&$ id=5669:folha-informativa-violencia-contra-as-mulheres $\&$ Itemid=820.

Örmon, K., Torstensson-Levander, M., Sunnqvist, C., \& Bahtsevani, C. (2014). The duality of suffering and trust: abused women's experiences of general psychiatric care-an interview study. Journal of clinical nursing, 23(15-16), 2303-2312.

Petricio, P. (2019). Assistência à Mulher Vítima de Violência Sexual. Revista Saúde-UNG-Ser, 12(1 (Esp), 28.

Pianucci, A. (2019). Saber cuidar: procedimentos básicos em enfermagem. Editora Senac.

Reis, M. J. D., Lopes, M. H. B. D. M., Higa, R., Turato, E. R., Chvatal, V. L. S., \& Bedone, A. J. (2010). Vivências de enfermeiros na assistência à mulher vítima de violência sexual. Revista de Saúde Pública, 44, 325-331.

Reis, M. J. D., Lopes, M. H. B. D. M., Higa, R., \& Bedone, A. J. (2010). Atendimento de enfermagem às mulheres que sofrem violência sexual. Revista Latino-Americana de Enfermagem, 18(4), 740-747. 
Research, Society and Development, v. 10, n. 2, e33210212595, 2021

(CC BY 4.0) | ISSN 2525-3409 | DOI: http://dx.doi.org/10.33448/rsd-v10i2.12595

Ribeiro, D. F. S., Gaspar, D. R. F. A., Vieira, G. O., \& Ferreira, R. S. (2016). O cuidado de enfermagem à mulher vitima de violência doméstica: uma experiência de acadêmicos de enfermagem. In $12^{\circ}$ Congresso Internacional da Rede Unida. http://conferencia2016.redeunida.org.br/ocs/index.php/congresso/2016/paper/view/3048.

Rosellò, F.T. (2009). Antropologia do cuidar. Vozes.

Santos, B. B. S., Dias, L. A., \& Carvalho, A. C. G. (2019). Atuação da enfermagem diante aos cuidados às mulheres vítimas da violência sexual. Revista Interdisciplinar Pensamento Científico, 5(5), 674-685.

Soares, A. O. (2019). Atuação do enfermeiro forense na violência contra a mulher - Um problema de Saúde Pública. Revista Ciências da Saúde e Educação IESGO, 1(2), 1-3.

Symes, L., Maddoux, J., McFarlane, J., Nava, A., \& Gilroy, H. (2014). Physical and sexual intimate partner violence, women's health and children's behavioural functioning: entry analysis of a seven-year prospective study. Journal of Clinical Nursing, 23(19-20), 2909-2918.

Santos, I. B. D., Leite, F. M. C., Amorim, M. H. C., Maciel, P. M. A., \& Gigante, D. P. (2020). Violência contra a mulher na vida: estudo entre usuárias da Atenção Primária. Ciência \& Saúde Coletiva, 25(5), 1935-1946.

Trigueiro, T. H., Silva, M. H. D., Merighi, M. A. B., Oliveira, D. M. D., \& Jesus, M. C. P. D. (2017). O sofrimento psíquico no cotidiano de mulheres que vivenciaram a violência sexual: estudo fenomenológico. Escola Anna Nery, 21(3), 1-7. 